\title{
LOS FOROS EN LA DESAMORTIZACIÓN. ETAPAS DE MENDIZÁBAL Y MADOZ
}

Xosé CORDEROTORRÓN

Dpto de Historia e Institucións Económicas, Facultade de C. Económicas e Empresariáis, Universidade de Santiago de Compostela; jose.cordero@usc.es

Resumen. El foro fue la forma predominante de propiedad de la tierra en Galicia desde la Edad Media hasta las primeras décadas del siglo XX. En el foro hay una propiedad compartida, con derechos del receptor de las rentas y otros del pagador de la renta. Al no ser abolido en la reforma agraria liberal española hubo de plantearse en la desamortización su forma de venta, o bien facilitando su adquisición por los pagadores de las rentas, con lo que desaparecería esa propiedad compartida y se transformaría en una propiedad plena, o bien vendiéndolos en subasta pública al mayor postor, con lo que persistiría esta forma de propiedad.

En la etapa desamortizadora de Mendizábal se optó por la venta en pública subasta, con la consiguiente persistencia del foro, que tan solo cambió de propietarios, pasando en su mayor parte a manos de la burguesía. Por el contrario, en la etapa desamortizadora de Madoz se facilitó la adquisición de las rentas forales por los campesinos (redención). La redención de las rentas forales en la desamortización de Madoz supuso el inicio del cambio del régimen de propiedad en Galicia con la transformación de los campesinos en propietarios plenos de sus tierras.

Palabras clave: Desamortización, foro, propiedad compartida, propiedad plena redención, Galicia.

\section{Title: The foros in the disentailment. Stages of Mendizábal and Madoz.}

Abstract: The foro was the predominant form of land ownership in Galicia from the Middle Ages to the early twentieth century. The foro is a shared ownership, with rights of the recipient of the income and of the payer of income. The foro was not abolished in the Spanish liberal agrarian reform so during the disentailment the form of sale was called into question, whether easing their acquisition by the payer of rents, what would make this shared property disappear becoming a wholly owned one, or selling it in a public auction to the highest bidder, which would make this form of ownership remain.

During the stage of Mendizabal disentailment the option of the public auction was chosen, due to this the foro remained as form of ownership with a change in the owners of the properties, mostly falling into bourgeoisie's hands. On the contrary, during the stage of Madoz disentailment the acquisition of the leasehold rents by the peasants (redemption) was eased. The redemption of the leasehold rents during the disentailment of Madoz marked the beginning of the change of ownership in Galicia with the transformation of peasants into full owners of their land.

Keywords: Disentailment, foro, shared ownership, wholly owned, redemption Galicia.

\section{INTRODUCCIÓN}

El foro era un censo con unas características similares a la enfiteusis pero con una evolución histórica peculiar ${ }^{1}$.

${ }^{1}$ Según Jacobo Gil Villanueva: "Hasta la Real Provisión de 11 de Mayo de 1763, examinadas las cosas sin pasión, me parece que se puede sostener que los foros eran verdaderas enfiteusis" (Gil, 1880). Puede verse una síntesis de las distintas posiciones sobre las características teóricas del foro en Fernández (1979). 
La abundante bibliografía sobre la desamortización en España se ha centrado en la enajenación de fincas, prestando muy poca o (la mayor parte de las veces) ninguna atención a la enajenación de los censos (Clavero, 1980; Díez, 1986; Congost, 2009).

En el Diccionario de Madoz, las rentas enajenadas en la desamortización figuran con el nombre de foros y censos, denominaciones genéricas de utilización habitual en la época para designar figuras similares a las enfiteusis, las primeras, y a los censos consignativos, las segundas². Para abreviar, denominamos rentas al conjunto de foros y censos.

\section{LA ENAJENACIÓN DE LAS RENTAS EN LA ETAPA DE MENDIZABAL}

Los Estados demostrativos de los capitales de foros, enfiteusis o arrendamientos anteriores al año 1800 y censos vendidos de la Gaceta de Madrid indican las ventas por provincias entre febrero de 1839 y julio de $1844^{3}$. Al analizar la distribución provincial de las ventas de rentas, comprobamos que entre 1839 y 1844 las ventas de las rentas gallegas suponen las siete octavas partes del número de ventas de rentas en España y las dos terceras partes de su valor total. Cifras muy superiores al peso de las rentas gallegas en España ${ }^{4}$. Una prueba de la fuerte concentración de las ventas de rentas en Galicia es que las de una de sus cuatro provincias, A Coruña, suponen la cuarta parte del total de España.

Si a Galicia le añadimos las dos comunidades vecinas tenemos más de las nueve décimas partes del total de ventas de rentas en España. Según los datos de la Gaceta de Madrid, la venta de rentas entre 1839 y 1844 era un asunto mayoritariamente gallego, al que eran ajenas la mayor parte de las provincias españolas ${ }^{5}$.

Camilo Labrador en su libro Economía Político-Práctica nos da el estado de las ventas de ambos cleros entre 1836 y 1849; distingue entre el clero regular y el secular, y aporta los datos anuales de ventas de fincas de cada uno de ellos y de ventas y redenciones de rentas del clero regular6.

Los censos y foros suponían, según Labrador (1850), el 17,3\% del total de las enajenaciones de bienes y rentas del clero regular. Además, la capitalización de las rentas redimidas ascendía a algo menos de la mitad de la de las rentas vendidas ${ }^{7}$

Hay diferencias en la evolución cronológica de las ventas y las redenciones. Las ventas de foros se inician tarde en comparación con las redenciones porque hubo que esperar hasta que la Circular de 30 de junio de 1838 ordenase la puesta en venta de "foros, enfiteusis y arrendamientos antiguos". Antes de ese momento, se había declarado, en marzo de 1836, el estado de redención de los censos ${ }^{8}$ y en mayo de 1837 se dio un plazo de seis meses

2 Estas denominaciones genéricas, con el significado indicado, aparecen repetidamente en la Gaceta de Madrid, en los Anuarios Estadísticos y en libros como los de Madoz (1846-1850), Labrador (1850) y Turza (1859).

${ }^{3}$ Dejan de publicarse en julio de 1844 hasta el mismo mes de 1847, año en el que sólo se publica el de ese mes y el del siguiente.

${ }^{4}$ En julio de 1845, según las cifras de Madoz (1846-1850), las rentas gallegas suponían la séptima parte del valor de tasación total de las del clero regular y secular español (Cordero, 2012).

5 Pueden verse los datos por provincia en Apéndice 1.

6 Habla de "venta de foros" y de "censos redimidos" del clero regular entre 1836 y 1849, aunque en realidad, tal como indica la Gaceta de Madrid, tanto los censos como los foros fueron objeto de venta y de redención.

7 La capitalización de la redención son 168.307.637 reales y la de la venta 339.369.316 reales (Labrador, 1850).

8 Real Orden de 5 de marzo de 1836. La Real Orden de 10 de abril de 1836 aclaraba que en las fincas 
para la redención de los foros ${ }^{9}$. La Circular de la Dirección de Arbitrios de Amortización de 30 de junio de 1837 fijaba una capitalización del 3 por ciento para todo tipo de censos, pero, en un cambio de gran trascendencia, la Real Orden de 23 de abril de 1838 rectificó la capitalización, dejándola en el $1 \frac{1}{2}$ por ciento ${ }^{10}$. La duplicación del capital preciso para redimir fue un grave obstáculo a la redención ${ }^{11}$.

A finales de 1840 se abre un nuevo plazo para redimir los censos ${ }^{12}$ que explica, en parte, un alza de las redenciones entre 1840 y 1842, con una amplitud temporal que puede ser causada por la demora existente entre el momento de la solicitud y el de la aprobación de la redención ${ }^{13}$. Las nuevas leyes de 1847 y 1848 señalando un nuevo término para la redención de los censos ${ }^{14}$ (en el último año se autorizan de nuevo las redenciones de foros) son la clave de un gran incremento de las redenciones en 1848 y 1849, que además se vieron muy favorecidas por la fuerte caída en esos momentos de las cotizaciones de los títulos con que se pagaban ${ }^{15}$.

A partir de 1844 disminuye significativamente el peso de Galicia en la venta de rentas ${ }^{16}$. Sucede igual que en Galicia en las otras dos provincias, Oviedo y Burgos, que se habían significado más en la venta de rentas hasta $1844^{17}$. Las ventas de rentas hasta 1844 de

en "enfiteusis y foros" sólo se vende el dominio directo y nunca el útil. La Real Orden de 28 de septiembre de 1836 facilitaba la forma de pago, que podía ser en títulos de la deuda o en metálico por el valor que tuviesen los títulos en la Bolsa de Madrid.

9 El Real Decreto de 31 de mayo de 1837 dio un plazo de medio año para solicitar la "redención de cargas o rentas exigidas con título de foro, enfiteusis o arrendamiento, cuya fecha sea anterior al año $1800 "$ ", transcurrido el plazo las rentas no redimidas deberían de ponerse en venta en subasta pública al mejor postor. Sobre la polémica parlamentaria para la elaboración de esta ley ver Carmona y Cordero (1980); Cordero (1982) (1986) (2012); Vallejo (1991) (1992) (1993).

10 Quien primero estudió esta rectificación fue Moro (1981a).

11 Se ordenó la rectificación de las redenciones que no hubiesen sido pagadas y muchos de los que habían solicitado las redenciones "desistieron luego que se enteraron" de que las capitalizaciones eran del 66 2/ 3 al millar. Archivo Histórico Nacional, Hacienda, Actas de la Junta de Venta de Bienes Nacionales, leg. 3970.

12 Decreto de la Regencia de 9 de diciembre de 1840. En este decreto se excluían expresamente los foros. Además la Ley de 14 de agosto de 1841 abre un plazo para la redención de los censos de población del antiguo reino de Granada.

13 Hay que tener en cuenta que se siguen redimiendo foros porque muchas solicitudes de redenciones de foros efectuadas en 1837 y 1838 fueron aprobadas con mucha demora, y además también influye la ley de 1841 de redención de los censos de población y la tardía publicación en Navarra, en 1840, del decreto de 31 de mayo de 1837.

14 Una Real Orden de 26 de septiembre de 1847 señalaba un nuevo término hasta el 31 de diciembre del mismo año para solicitar la redención de los censos. Como había sucedido con la anterior prorroga también se excluían los foros. Parecía suceder lo mismo con el Real Decreto de 7 de abril de 1848, pero la Real Orden de 6 de octubre de 1848 resuelve que todos los foros estaban comprendidos en su artículo 5ㅜ, concediendo el plazo de seis meses para solicitar la redención.

15 En el período entre 1836 y 1849 coinciden en el mismo año, 1849, el máximo volumen de redenciones y la menor cotización media de los títulos del 4 y del 5 por ciento $(10,96$ y 10,07) (Labrador, 1850). Ver también Villares (1994).

16 Se reduce en A Coruña, Lugo y Ourense, en Pontevedra solo se conocen los datos hasta 1844, y Galicia pasa de representar el 69,04\% al 49,38\%. La mayor amplitud temporal de los datos de las investigaciones provinciales (toda la etapa de Mendizábal, con la excepción de Pontevedra) que la de Camilo Labrador (hasta 1849), refuerza la tesis de la disminución (Apéndices 1 y 2).

17 En Asturias pasa del 10,69\% al 6,16\% y Burgos del 7,82\% al 5,92\%. En León, en cambio, se 
todas las provincias gallegas más Asturias, Burgos y León, suponían 89,79\% del total de España, mientras que hasta 1849 se reduce ese porcentaje al 63,68\%. Obviamente, este descenso significa que hay un incremento importante del resto de España.

Es a partir de 1844 cuando empiezan a venderse de forma significativa rentas en otras partes de España, fuera de Galicia y las otras tres provincias donde se habían concentrado las ventas hasta 1844. Así se deduce por los anteriores datos y por las investigaciones existentes (Molí, 1975; Sánchez Recio, 1986; Ortega, 1982; Naranjo, 1997, Cordero, 2012).

En cuanto a los tipos de rentas vendidas, en Galicia, la comunidad con mayor concentración de ventas, hay un claro predominio de los foros. En A Coruña suponen cerca de las tres cuartas partes de las rentas vendidas ${ }^{18}$; en Pontevedra ${ }^{19}$ y Lugo ${ }^{20}$ tienen aún más peso proporcionalmente. Los restantes componentes de las enajenaciones son los arrendamientos antiguos ${ }^{21}$, las "rentas" 22 , los censos consignativos y los subforos ${ }^{23}$.

En A Coruña, cerca de las tres cuartas partes de las rentas (72\% de su valor) son adquiridas por la burguesía, entendida como un grupo social amplio, dentro del cual los funcionarios y profesiones liberales tienen un protagonismo muy inferior ( $11 \%$ del valor total de las rentas) del que tuvieron los comerciantes e industriales, que suponen la quinta parte, $21,5 \%$, de los adquirentes y compran las seis décimas partes de las rentas vendidas (61\% de su valor). Como en A Coruña, también en Lugo, Pontevedra, Asturias y el Bierzo la burguesía es la gran beneficiada de las ventas ${ }^{24}$. Por el contrario, en A Coruña, como también sucede en Pontevedra, los labradores tienen escasa relevancia ${ }^{25}$; en Lugo,

mantiene el porcentaje (Apéndices 1 y 2).

18 Con el 73,8\%, del número de rentas y el 78,5 por ciento de su valor (Cordero, 2012).

19 Suponen el 98,5\% del número y valor de las rentas vendidas (Vallejo, 1993).

20 En Lugo son el 94,8\% del número y el 93,2\% del valor de las rentas desamortizadas (Villares, 1994).

21 Son algo más de la décima parte de las rentas vendidas en A Coruña (Cordero, 2012); en Pontevedra solo hay 61 de un total de 4.438 (Vallejo, 1993). En Lugo suponen el 5\% del número de rentas (Villares ,1994).

${ }^{22}$ Las "rentas" (las diferenciamos del conjunto de rentas con las comillas) se definen por exclusión: son las que no figuran en la documentación con ninguna de las denominaciones restantes. Las "rentas" suponen el 5,0\% del valor total de las rentas vendidas en A Coruña (Cordero, 2012)

23 Los censos consignativos representan menos del 0,5\% de las rentas vendidas en A Coruña, Pontevedra, Lugo y León. Los subforos en A Coruña son el 0,4\% del valor total de las rentas vendidas (Cordero, 2012; Vallejo, 1993; Villares, 1994; Aguado, 2002).

24 En la provincia de Lugo adquiere dos tercios del total (Villares, 1994). En Pontevedra, la "clase mercantil estrictamente considerada" adquiere más de un tercio de las rentas vendidas, y en un sentido más amplio, el grupo formado por los compradores con residencia en las ciudades y con dedicación no agrícola tienen unas adquisiciones que suponen el 84,2\% del total desamortizado (Vallejo, 1993). En Asturias, las adquisiciones de la "burguesía" suponen el 80,8\%, del valor total rematado, aunque, como indica José María Moro, hay que tomar las cifras con "todas las precauciones y provisionalidades" porque, por ejemplo, incluyó dentro de la burguesía a la nobleza (Moro, 1981a). En el Bierzo, según García (1994), la clase social más beneficiada es la "burguesía", que se hace con el $80 \%$ de los remates y el $88 \%$ del valor en remate, aunque, como señala García Fernández, el grupo que califica de burgueses es bastante confuso, pues incorpora a este grupo, junto a los comerciantes, profesiones liberales y funcionarios, a nobles con cargos políticos, hacendados milicianos nacionales, hidalgos etc. El problema está en su conceptualización de burguesía: "Este conjunto de personas, aunque de diferente procedencia y fortuna, que se contrapone a las clases bajas lo podemos calificar de burguesía".

25 En A Coruña, son el grupo social más numeroso entre los adquirentes pero compran pocas rentas, 
su participación, pese a ser reducida, es algo superior ${ }^{26}$. Es algo más relevante, a excepción de Pontevedra, la participación de la nobleza, junto con los hidalgos y hacendados, en A Coruña superan ligeramente la décima parte de las rentas vendidas ${ }^{27}$; en Lugo se eleva su participación hasta las dos décimas partes ${ }^{28}$.

Hablando siempre del reducido número de provincias con datos conocidos, Galicia no tenía en las redenciones la clara hegemonía en España que tenía en las ventas. Las provincias gallegas son rebasadas por Navarra. La provincia de A Coruña ocupa un segundo puesto porque fue especialmente beneficiada ${ }^{29}$ por la Real Orden de 6 de octubre de $1848^{30}$.

La exigüidad de las redenciones en comparación con las ventas nos plantea la necesidad de preguntarnos la razón por la que la mayor parte de los pagadores de rentas enajenadas en la etapa desamortizadora de Mendizábal renunciaron a la redención.

Rafael Vallejo en la provincia de Pontevedra y nosotros en las de A Coruña y Lugo, comprobamos que, al contrario de lo que afirmaron Moro, Villares y Aguado31, no existieron prorrogas sucesivas para solicitar la redención de los foros. En las redenciones de foros se siguió inicialmente el período de tiempo dispuesto en el Real Decreto de 31 de mayo de 183732 y transcurrido ese plazo los posibles redimentes de foros tuvieron que esperar 10 años para que se abriese un nuevo período de redención ${ }^{33}$. Lo mismo sucede en Ourense, donde las pocas redenciones que hay antes de 1849 se producen en 1838 (Domínguez et al., 1995), y así, también, como veremos a continuación, lo reconoció el legislador.

La Junta de Ventas de Bienes Nacionales, en sesión de 28 de junio de 1848, respondió inicialmente con una negativa ${ }^{34}$ a una consulta del intendente de A Coruña sobre si los foros gallegos estaban comprendidos en el Real Decreto de 7 de abril de $1848^{35}$. En este

2,3\% del valor de las rentas vendidas. En Pontevedra es el 1,7\% del valor de subasta (Vallejo, 1993).

26 En Lugo, tienen el 9,6\% del valor total de los bienes desamortización. Si se les agrega, además, la baja hidalguía rural, se llega al 15\% (Villares, 1994).

27 Con el 12,7\% del valor total de las rentas vendidas (Cordero, 2012). En Pontevedra era el 2,5\% de su valor de subasta (Vallejo, 1993).

28 Con el 20,3\% del total rematado (Villares, 1994).

29 La Colegiata de Caaveiro (provincia de A Coruña) había estado excluida de la posibilidad de redención. La Real Orden de 6 de octubre de 1848 acuerda la redención de los foros de esa Colegiata. 30 Con los datos disponibles de las investigaciones existentes tras A Coruña están Ourense y Lugo (Apéndice 3)

31 Moro (1981르), Villares (1994) y Aguado (2002) coinciden en afirmar que los redimentes no tuvieron problemas de limitación de plazos.

32 Recordamos que Vallejo (1993) sólo estudia las redenciones hasta 1844. En A Coruña Cordero (2012). En Lugo utilicé los expedientes de redención disponibles (legajos 247, 248, 294, 300, 324, 401, 427, 432, 436, 437, 444, 451, 453, 454, 455, 462, 476, 478, 497, 500) del fondo Desamortización del Arquivo Histórico Provincial de Lugo y el Libro auxiliar de c/ c de redimentes del clero regular, L 4035, del fondo Facenda del mismo archivo.

33 Vallejo (1993) (1995) y Cordero (2012)

34 “...no están comprendidos en el citado decreto, porque en cuanto a la redención de los foros, enfiteusis o cargas exigidas por arriendos muy largos se dispuso ya lo conveniente en el Real Decreto de 31 de mayo de 1837, no siendo por lo tanto objeto de la redención" Archivo Histórico Nacional, Hacienda, Actas de la Junta de Venta de Bienes Nacionales, leg. 3975.

35 Real Decreto, mandando proceder a la venta de todos los bienes de las encomiendas vacantes de las cuatro órdenes militares, de las ermitas, santuarios, hermandades y cofradías. 
Real Decreto se ordena la enajenación de los "censos de todas clases que son hoy propiedad de la nación", y en el artículo 5o abría un nuevo plazo de dos meses para pedir la redención. Disconforme con la resolución de la Junta de Bienes Nacionales, el intendente propuso que la redención concedida en el Real Decreto se hiciese extensiva a los foros de Galicia. Esta proposición acabó siendo aceptada: "La Sra cree digna de la consideración del gobierno la cuestión de los foros de Asturias y Galicia que solo en el nombre se diferencian de los censos perpetuos de las demás provincias del Reino que en varias épocas han gozado del beneficio de prórroga para la redención que a los primeros se les niega en cuanto son iguales los efectos que con tanta resignación están sufriendo los infelices y laboriosos colonos de dichas provincias..." 36 .

A partir de ese momento se va abrir un nuevo período de redención de los foros. En respuesta a un expediente instruido a raíz de una reclamación de D. Francisco Riovó y Roldán, por si y otros vecinos, por la exclusión de la Colegiata de Caaveiro (provincia de A Coruña) de los beneficios de la redención de la ley de 31 de mayo de 1837, ocasionado por el error de haberla considerado del clero secular, la Real Orden de 6 de octubre de 1848 resuelve que los foros de esa Colegiata y "todos los demás" estaban comprendidos en el artículo 5ํ del Real Decreto 7 de abril de 1848, por lo que se concede el plazo de seis meses para solicitar la redención.

Una Circular del 31 de agosto de 1849 les recuerda a los intendentes provinciales que, transcurrido el término de seis meses, tenían que proceder a la venta de los censos y foros no redimidos. Pero las reclamaciones de varios colonos de Galicia y Asturias alegando no haber podido solicitar la redención de foros en el plazo señalado en la Real Orden de 6 de octubre de 1848 por no haberla conocido a tiempo, dieron pie a que se promulgase la Real Orden de 18 de junio de 1850 por la que se abría un nuevo plazo de 3 meses para solicitar la redención "para que puedan convertirse en propietarios y mejorar el cultivo de sus fincas", además se instaba a que se publicase esta resolución "hasta en las poblaciones y caseríos más pequeños" y a que los párrocos la hiciesen "saber a sus feligreses en la primera festividad", según decía el Boletín Oficial de la Provincia de La Coruña de fecha 24 de julio de 1850; a partir de ese momento empezaba a contar el plazo ${ }^{37}$.

La apertura en 1848 de un nuevo plazo de redención de los foros, tras diez años en los que sólo estaba autorizada su venta ${ }^{38}$, el nuevo plazo concedido en 1850, la propia redacción de la Real Orden que lo autorizaba y las facilidades crecientes para redimir las rentas de las Encomiendas ${ }^{39}$, nos sugieren, siguiendo a Ramón Villares, que se estaba produciendo un cambio de rumbo de la política redentorista ${ }^{40}$. Pero no podemos olvidar que en esta etapa desamortizadora en la mayor parte de los años no hubo la posibilidad de redimir los

\footnotetext{
36 Archivo Histórico Nacional, Hacienda, Actas de la Junta de Venta de Bienes Nacionales, leg. 3975.

${ }^{37}$ En la provincia de A Coruña, las redenciones de foros en 1849 y 1850 fueron bastante numerosas en comparación con períodos precedentes. Entre 1848 y 1850, se redimen 723 rentas con un valor de capitalización de 4.792.177,04 reales, en todo el período restante entre 1838 y 1852, excluidos esos tres años, se redimen 63 con una capitalización de 1.601.376,97 reales.

38 Sin embargo, en Navarra, el decreto de 31 de mayo de 1837 se publicó en el Boletín de la provincia el 6 de febrero de 1840, porque en su momento, a causa de la guerra, no había podido circular por toda la provincia (Donezar,1975).

39 Real Decreto del 6 de septiembre de 1850 y Decreto de 7 de marzo de 1851 (Villares, 1994).

40 Aunque Villares vincula ese cambio sobre todo a las modificaciones con cada vez más facilidades para la redención de la normativa desamortizadora de la Orden de San Juan de Jerusalén (Villares, 1994).
} 
foros. La cortedad del primer plazo para solicitar la redención, durante seis meses en 1837-183841, agravada, además, por la duplicación del precio de la redención y por la reducción a la mitad, en comparación con la venta en pública subasta de las rentas, de los plazos de pago, son, todos ellos, los factores determinantes de la exigüidad de las redenciones. Cuando se reanuda la posibilidad de redimir los foros, en 1848, la redención estuvo favorecida por una fuerte caída de las cotizaciones de los títulos de la deuda con que se pagaba (Labrador, 1850), pero, en ese momento, las redenciones ya no podían ser masivas porque, en Galicia, ya se habían enajenado en pública subasta casi todos los foros del clero regular masculino (Cordero, 2012).

Hasta finales de la década de los cuarenta no hubo voluntad política para facilitar la redención de los foros. Villares (1994), Aguado (2002), Moro (1981aㅡ), Vallejo (1991) y la propia Administración ${ }^{42}$ nos hablan de la presión e influencia de grupos burgueses en favor de la venta en subasta pública de los foros. Las élites económicas de Galicia (burguesía, foristas y subforistas) defendían, en ese momento, la pervivencia del foro y con ella la extracción de recursos de la mayor parte de la población para un grupo reducido del que formaban parte 43 .

Posteriormente, cuando se discuta la normativa de redención en la etapa de Madoz, el legislador también apuntará otra razón de la preferencia en la etapa de Mendizábal de la venta en pública subasta sobre la redención. Según el diputado Alonso Martínez, en la etapa de Mendizábal se habían establecido restricciones a la redención "con el fin de allegar recursos para el Tesoro", es decir, se dificultó la redención con el fin de maximizar los ingresos a través de la subasta pública de las rentas ${ }^{44}$. Para Villares (1994), sin embargo, los reducidos índices de cotización de las pujas de rentas en la provincia de Lugo no justifican un desvío de las rentas a la subasta pública en lugar de la redención ${ }^{45}$. Por una razón similar, tampoco estaría justificado en las provincias de León y Pontevedra46. Pero no sucede lo mismo en Asturias y en la provincia de A Coruña, ambas con una cotización casi idéntica ${ }^{47}, 143 \%$, muy superior a la de las anteriores provincias, y donde,

41 El plazo de 6 meses empezaba a contar desde el momento en que se publica el Real Decreto en el Boletín Oficial de la provincia. En A Coruña se publicó en un suplemento al Boletín Oficial de la Provincia de La Coruña de fecha 24 de julio de 1837.

42 La Circular de 30 de junio de 1838 ordenaba la puesta en venta de "foros, enfiteusis y arrendamientos", atendiendo a que la Junta de Ventas de Bienes Nacionales no deseaba "retrasar más la enajenación de dichos capitales, que solicitan con repetidas instancias los que desean interesarse en su adquisición".

43 En nuestra opinión, utilizando términos de Acemoglou y Robinson, el foro era una institución económica extractiva que lastraba, por sus características de cargas perpetuas y en especie, el crecimiento de la economía gallega (Acemoglou y Robinson, 2012). Desde otra perspectiva, para Carmona (1990) las adquisiciones de rentas por la burguesía hicieron que quedase "descabezado una vez más el posible surgir de una burguesía que asumiera la tarea de modernizar la estructura agraria de forma que pudiera ser la base de un desenvolvimiento capitalista autóctono".

44 Diario de las Sesiones de Cortes. Congreso de los Diputados. Legislatura de 1865 a 1866 (1866: apéndice 20 al número 59 ).

45 La cotización en Lugo es 112\% (Villares, 1994).

46 La cotización en León es del 109\% (Aguado, 2002). La cotización en Pontevedra es del 110\% (Vallejo, 1991).

47 La cotización de foros y censos en Asturias es del 143,8\% (Moro, 1981a). En la provincia de A Coruña es del 142,7\% (Cordero, 2012). 
por tanto, sí estaba justificada la preferencia de la Administración por la venta en pública subasta. Lo mismo sucedía en el conjunto de España ${ }^{48}$.

El elenco de los redimentes tiene que reflejar, no puede ser de otra forma, la vinculación previa con la tierra. Únicamente puede redimir quien detente el dominio útil de fincas en enfiteusis, foros, arrendamientos antiguos u otro tipo de contratos similares, o tenga fincas hipotecadas en garantía de censos. Los labradores, que tan escaso papel tuvieron en la adquisición de rentas en pública subasta, representan, en A Coruña, la parte mayoritaria de los redimentes, con las cuatro quintas partes, 80,2\%, de los redimentes con profesión conocida y las seis décimas partes, 60,4\%, de su renta (Cordero, 2012). También en Lugo, Ourense y Asturias es mayoritaria la participación del campesinado en la redención ${ }^{49}$. Tras los campesinos, el siguiente grupo social con mayor participación en las redenciones es el formado por la nobleza, hidalgos y hacendados ${ }^{50}$.

\section{LA ENAJENACIÓN DE LAS RENTAS EN LA ETAPA DE MADOZ.}

Al contrario de lo que sucedió en la anterior etapa desamortizadora, en la desamortización de Madoz casi todas las rentas que se enajenan se redimen ${ }^{51}$. Las redenciones empezaron con mucho dinamismo ${ }^{52}$ y son masivas ${ }^{53}$.

Conocemos la distribución provincial de las redenciones entre 1855 y 1860 por información de la Gaceta de Madrid ${ }^{54}$ y de los Anuarios Estadísticos ${ }^{55}$. La región que más destaca ahora es Andalucía, seguida por Castilla León, Cataluña y Galicia. Entre las cuatro suponen el 58,1\% del número y 56\% de capitalización total (Cordero, 2012).

Los cambios de ritmo en las ventas y redenciones están determinados por las modificaciones del marco legal. Tras el Bienio Progresista se paralizan las enajenaciones, que se reanudan en 1859 con un nuevo plazo para redimir las rentas pertenecientes al Estado y a corporaciones civiles. Finalizado el plazo de redención, en mayo de 1860 se

48 Según la Gaceta de Madrid la cotización de los foros vendidos hasta agosto de 1847 fue del 125\%. Según Labrador (1850) la cotización de los foros vendidos hasta 1849 fue del 137,6\%.

49 En Lugo, los campesinos redimen el 62,4\% del valor de la renta (la baja hidalguía redime un $11,1 \%$ adicional), en Ourense el $54 \%$ más una parte mayoritaria de otro $21 \%$ de redenciones mixtas de hidalgos y campesinos (Villares, 1994; Domínguez et al. ,1995; Moro, 1981a). En Pontevedra, en cambio, según Vallejo (1991), es muy minoritaria la participación del campesinado, 4,6\% del total.

50 En A Coruña suponen 21,6\% del valor de la renta redimida. En Lugo es el 18,2\% del valor de capitalización de las rentas redimidas. En Ourense es el 15,4\% (más una parte minoritaria del $21,2 \%$ de redenciones mixtas). En Pontevedra, en cambio, este porcentaje se eleva al $71,1 \%$ del valor de tasación de las rentas (Cordero, 2012; Villares, 1994; Domínguez et al. ,1995; Vallejo, 1991).

51 Las ventas suponen un cincuentavo del valor total de adjudicación de las rentas entre 1855 y 1867 (Apéndice 4).

${ }^{52}$ La ley de 1 de mayo de 1855 concede un plazo de seis meses para solicitar la redención. La Instrucción de 31 de mayo de 1855 regula el proceso para efectuar las redenciones. La Ley Aclaratoria de 21 de febrero de 1856 amplia seis meses más el período de redención. En esta etapa desamortizadora los censos y los foros tienen los mismos tipos de capitalización y las mismas etapas de redención y venta.

53 Entre 1855 y 1860 se redimen en España 135.560 rentas con un valor de capitalización de 248.759.231 reales (Cordero, 2012).

54 Gaceta de Madrid de fecha 27 de febrero de 1857

55 Anuarios Estadísticos de España de 1858, 1859-1860 y 1860-1861. 
ordena la venta de esos censos ${ }^{56}$. De forma paralela, se estaba llegando a un consenso con el clero para la indemnización y enajenación de sus bienes y rentas. En abril de 1860 se publica el convenio con la Santa Sede para proceder a la permutación de los bienes y rentas del clero por títulos de la deuda ${ }^{57}$, y en ese mismo mes del año siguiente se aclara el procedimiento de venta y redención ${ }^{58}$. A partir de entonces la cronología de ese proceso depende de las permutaciones, que se efectúan en cada diócesis en momentos distintos.

En 1862, con un nuevo plazo de redención de los censos del Estado y de corporaciones civiles $^{59}$, hay un fuerte incremento de las redenciones porque además empiezan a redimirse los censos de las diócesis con las que se va llegando a acuerdos de permutación. Según se van produciendo los convenios con cada diócesis así se van abriendo períodos primero de redención y luego de venta de las rentas eclesiásticas ${ }^{60}$.

El volumen masivo de redenciones tiene que ser explicado por su abaratamiento ${ }^{61}$ y por las sucesivas prórrogas para la solicitud de redención. Capitalizaciones reducidas y plazos amplios facilitan, obviamente, la redención.

La pregunta que nos tenemos que hacer es por qué se dan ahora unas facilidades para redimir que no se habían dado antes. La respuesta es compleja. En primer lugar, gran parte de las rentas enajenadas en esta etapa se caracterizaban por ser de reducida cuantía y pertenecer a pequeñas instituciones eclesiásticas (iglesarios, fábricas parroquiales, cofradías etc.) dispersas por el territorio (Artiaga, 1991; Cordero, 2012), todo lo cual conllevaba altos costes de administración y cobranza. Frente a esa circunstancia, la burguesía disponía de más inversiones alternativas provechosas que las existentes en el período anterior; tales eran las propiedades plenas vendidas en la etapa de Madoz (más importantes, sobre todo en Galicia, que las vendidas en la anterior etapa ${ }^{62}$ ) y las nuevas posibilidades de inversión derivadas del proceso de crecimiento y modernización económica (Vallejo, 2011). Además, los altos costes de administración y cobranza de las rentas incentivaban al Estado a facilitar su enajenación y, asimismo, ahora, en la discusión parlamentaria, se percibe que había un sentimiento mayoritario de priorizar la reducción de cargas sobre la propiedad, por medio de la redención, sobre el incremento de ingresos con la venta en subasta pública63.

56 Real Orden de 21 de mayo de 1860.

57 La Ley de 4 de abril de 1860 publica y manda observar el Convenio celebrado con la Santa Sede en 25 de agosto de 1859 ,

58 Ley de 7 de abril de 1861

59 Ley de Presupuestos de 4 de mayo de 1862

60 En Galicia empiezan a enajenarse los correspondientes a la diócesis de Lugo en 1862, los de la de Tuy en 1863, los de Mondoñedo en 1864 y los de Santiago de Compostela en 1865 (Cordero, 2012)..

61 El tipo de capitalización en la Ley de 1 de mayo de 1855 era el 10\% para las rentas que no superasen los 60 reales y el 8\% para las de mayor valor. Las rentas de mayor valor también podían ser redimidas en 9 años y 10 plazos, en tal caso el tipo era del 5\%. En la Ley de 11 de marzo de 1859 hay un ligero encarecimiento de las redenciones: las rentas no superiores a 60 reales se redimirían al contado y con una capitalización del $8 \%$, las superiores a 60 reales cuando se redimen al contado pasan a tener un tipo del 6,5\%, y en las redenciones a plazos se pasó al 4,8\%. Se vuelve a la capitalización de 1855 en la Ley de 2 de septiembre de 1873. Hay nuevos tipos de capitalización, más favorables, en la Ley de 11 de junio de 1878.

62 En la provincia de A Coruña se vendieron, en la etapa de Mendizábal, 2.219 hectáreas de fincas rústicas, mientras que en la de Madoz esta cifra se eleva hasta 8.698 hectáreas (Cordero, 2012).

63 Puede verse en los discursos de Pascual Madoz y Alonso Martínez . Diario de las Sesiones de 
Al contrario de lo que sucedió en la desamortización de Mendizábal, en la de Madoz hay confusión en la documentación entre censos y foros ${ }^{64}$. No se puede hacer una diferenciación clara entre ambos ${ }^{65}$.

Ahora, en la etapa de Madoz, va a ser el momento de los labradores, en esta etapa sus redenciones van a ser masivas. Así sucede en la provincia de Pontevedra (Artiaga, 1991) y en la provincia de A Coruña (Cordero, 2012), donde suponen las tres cuartas partes, $75,1 \%$, de los redimentes con profesión conocida, que redimen entorno a las seis décimas partes del total de la renta de dichos redimentes, 58,7\%. Las ventas de rentas tienen escasa relevancia ${ }^{66}$.

\section{BALANCE GLOBAL Y CONCLUSIONES}

Hay grandes diferencias en la forma predominante de enajenación de las rentas en las etapas de Mendizábal y Madoz.

En la etapa de Mendizábal hay un predominio de las ventas de rentas sobre la redención. Esto supone la permanencia de la división de dominios -útil y directo- y la continuidad de cargas perpetuas sobre la propiedad que obstaculizan el crecimiento agrario. En esta etapa, las ventas de rentas en España están muy concentradas geográficamente en Galicia, Asturias y algunas provincias de Castilla León. En estas zonas había una apetencia por la adquisición de rentas que no existía en otras partes de España. En Cataluña, por ejemplo, apenas se venden las rentas que llegan a la subasta pública (Moli,1975; Solsona,1998).

Cuadro1. Venta y redención de rentas (reales). Provincia de A Coruña (1838-1919)

\begin{tabular}{|c|c|c|c|}
\cline { 2 - 4 } \multicolumn{1}{c|}{} & Número & Valor & Adjudicación \\
\hline Redención & 23.597 & $1.846 .039,2$ & $34.732 .340,4$ \\
\hline Venta67 $^{6}$ & 9.644 & $1.215 .387,4$ & $110.580 .476,3$ \\
\hline Total & 33.241 & $3.061 .426,6$ & $145.312 .816,7$ \\
\hline
\end{tabular}

Fuente: Cordero (2012)

Una razón por la que Galicia tiene tanto protagonismo en la venta de rentas está en que el clero regular gallego tenía pocas propiedades plenas y, en consecuencia, los inversores gallegos no tenían la disyuntiva, que sí existía en otras partes de España, entre la adquisición de propiedades plenas y la adquisición de rentas. Sabemos que, en España, donde existió esa disyuntiva los inversores optaron por las propiedades plenas (Naranjo, 1997).

En la etapa de Madoz, en cambio, las redenciones son masivas, y a ello contribuyó de forma decisiva la normativa de redención, mucho más favorable que en la etapa de

Cortes. Congreso de los Diputados. Legislatura de 1858 (1883:803-809); Legislatura de 1865 a1866 (1866: apéndice 2ํo al núm. 59)

64 Moro (1981b) Artiaga (1991) y Cordero (2012) constataron esta dificultad.

${ }^{65}$ Se puede hacer, en todo caso, una diferenciación entre las rentas en especie y las rentas en dinero. En Asturias y las provincias de Pontevedra y A Coruña las rentas en dinero suponían algo menos de un tercio del valor total de las rentas (Moro, 1981b; Artiaga, 1991; Cordero, 2012).

66 En la provincia de Pontevedra las redenciones suponen el 89,9\% del total de enajenaciones de rentas y el 88,6\% de su valor total de adjudicación, el resto son ventas y transmisiones de rentas. (Artiaga, 1991). En la provincia de A Coruña son el 96,7\% del valor de las rentas enajenadas y el 95,8\% de su valor de adjudicación (Cordero, 2012).

67 Incorporamos en la venta 67 trasmisiones (Cordero, 2012). 
Mendizábal, tanto por los plazos para redimir, mucho más prolongados y con prorrogas sucesivas, como por los tipos de capitalización, mucho menos onerosos. Con la redención se consolidan como propiedades plenas los dos antiguos dominios enfitéuticos o forales y se liberan de cargas censuales las propiedades agrarias.

En un balance global de las dos etapas desamortizadoras, quedaríamos con una impresión totalmente equivocada si basásemos nuestro análisis en los valores de adjudicación de las rentas ${ }^{68}$, porque, como hemos visto, las ventas de rentas se concentran en la etapa de Mendizábal, cuando la capitalización de la renta era mucho más elevada y la forma de pago era con títulos de la deuda muy desvalorizados, con una cotización entorno al $20 \%$ o al 10\%, incluso, a finales de la década de 1840. Así pues, el valor real de adjudicación de los foros en la etapa de Mendizábal era muy inferior del nominal, que es el que figura en el cuadro 1 como valor de adjudicación. Sucede lo contrario en la etapa de Madoz, donde, como sabemos, se concentran las redenciones, la capitalización era mucho más reducida y la generalidad de los pagos eran en metálico, con la consecuente coincidencia entre el valor nominal y el valor real de adjudicación. Para evitar los problemas derivados de las distintas capitalizaciones y formas de pago, lo correcto es emplear el valor de las rentas, de esta forma podemos comprobar que, en un balance global de las dos etapas desamortizadoras en la provincia de A Coruña, las rentas redimidas superan ampliamente a las vendidas tanto en número, $71 \%$ del total de las rentas enajenadas, como en valor, $60 \%$ de su valor total.

Con las redenciones forales de bienes nacionales se estaba iniciando un cambio del régimen de propiedad en Galicia, con la transformación de los detentadores del dominio útil foral, mayoritariamente campesinos, en propietarios plenos de sus tierras.

Pero esto solo era el inicio de un cambio que tendrá un largo recorrido, con episodios como la redención foral de 1873, paralizada a instancia de los detentadores del dominio directo - entre los que estaban los adquirentes de foros en la etapa de Mendizábal-, y que, como señala Bouhier (1979), en los foros privados -también los que se vendieron en subasta pública en la etapa de Mendizábal- fueron los rentistas los que impusieron unos términos nada benignos para la redención, mientras el Estado se abstuvo de intervenir hasta que en 1926 dictó un Decreto Ley de redención para proporcionar una indemnización ventajosa a los dueños del directo (Villares, 1978) y protegerlos, así, del peligro que suponía la fortaleza que habían llegado a adquirir las organizaciones antiforistas (Baz, 1996).

Todo este largo proceso de transformación de la propiedad tuvo dos tipos de efectos, por una parte, la eliminación de cargas fijas y perpetuas favoreció el crecimiento agrario, pero por otra, los pagos en concepto de redención supusieron una descapitalización transitoria de las explotaciones campesinas y un trasvase de recursos desde la agricultura hacia el Estado, en las redenciones de bienes nacionales, y hacia las ciudades, dentro y fuera de Galicia, donde residían los rentistas (foristas, subforistas y herederos de los adquirentes de rentas en la etapa desamortizadora de Mendizábal).

68 Según el valor nominal de adjudicación, las redenciones en la provincia de A Coruña solo supondrían el 23,9\% del valor total de enajenaciones de rentas. Este es un porcentaje muy similar al calculado por Vallejo (2011) para el agregado de las provincias de Lugo y Pontevedra. Con esas cifras tendríamos que concluir, erróneamente, que las rentas redimidas fueron muy minoritarias frente a las vendidas en pública subasta. 


\section{BIBLIOGRAFÍA}

ACEMOGLOU, D. y ROBINSON, J. A. (2012): Why Nations Fail. New York, Crown Publishers. AGUADO CABEZAS, E. (2002): La desamortización de Mendizábal y Espartero en la provincia de León (1836-1851). León, Universidad de León, Secretariado de Publicaciones y Medios Audiovisuales.

ARTIAGA REGO, A. (1991): A desamortización na provincia de Pontevedra (1855-1900). Pontevedra, Diputación Provincial, Servicio de Publicacións.

BAZ VICENTE, Ma. J. (1996): Señorío y propiedad foral de la alta nobleza en Galicia, siglos XVI-XX: La Casa de Alba. Madrid, Ministerio de Agricultura, Pesca y Alimentación.

BOUHIER, A. (1979): La Galice. Essai geografique d'analise et d'interpretation d'un vieux complexe agraire. La Roche-sur-Yon (Vendée), Imprimerie Yonnaise.

CARMONA BADÍA, X. (1990): El atraso industrial de Galicia. Auge y liquidación de las manufacturas textiles (1750-1900). Barcelona, Ariel.

CARMONA BADÍA, X. y CORDERO TORRÓN, X. (1980): "Introducción á análise da Redención Foral de Mendizábal en Galicia”. Revista galega de estudios agrarios, no 3, pp. 37 a 54.

CLAVERO SALVADOR, B. (1980): "Foros y rabassas. Los censos agrarios ante la revolución española”. Agricultura y Sociedad, no 16, pp. 27-69 y no 18, pp. 65-99.

CONGOST COLOMER, R. (2007): Tierras, leyes, historia. Estudios sobre "la gran obra de la propiedad". Barcelona, Crítica.

CONGOST COLOMER, R. (2009): "De censatarios de la Iglesia a deudores del Estado. Más reflexiones sobre el proceso desamortizador y la revolución liberal en España" En BODINIER, B., CONGOST, R. y LUNA, P. F. (eds.): De la Iglesia al Estado. Las desamortizaciones de bienes eclesiásticos en Francia, España y América Latina. Zaragoza, Prensas Universitarias de Zaragoza, pp. 377-407.

CORDERO TORRÓN, X. (1982): "Notas críticas sobre a desamortización en Galicia”. Grial, anexo 1, pp. 121-130.

CORDERO TORRÓN, X. (1986): “La redención foral en la provincia de La Coruña ante el proceso desamortizador". En VV.AA.: Desamortización y Hacienda Pública, Madrid, Ministerio de Agricultura, Pesca y Alimentación, tomo I, pp. 191-206.

CORDERO TORRÓN, J. (2012): La desamortización en la provincia de A Coruña. Etapas de Mendizábal y Madoz. Santiago de Compostela. Tesis Doctoral Inédita.

DÍEZ ESPINOSA, J.R. (1986): “La desamortización de censos" y "La redención y venta de censos”. En Rueda, Germán: La desamortización de Mendizábal y Espartero en España. Madrid, Cátedra, pp. 76-84 y pp. 116-132.

DOMÍNGUEZ CASTRO, L. (1992): “Os Cenobios cistercienses do Ribeiro na desamortización de Mendizábal, tipoloxía dos bens e socioloxía dos compradores". En Actas Congreso Internacional sobre San Bernardo e o Cister en Galicia e Portugal. 17-20outubro 1991. Ourense, Xunta de Galicia, vol. I, pp. 463-474.

DOMÍNGUEZ CASTRO, L., BASALO ÁLVAREZ, M. T. y LOSADA RODRÍGUEZ, M.J. (1995): "Foros y desamortizaciones en la provincia de Ourense (1821-1851). Algo se mueve". En DONEZAR, J.M. y PÉREZ LEDESMA, M, (eds.): Antiguo Régimen y liberalismo. Homenaje a Miguel Artola. 2. Economía y sociedad. Madrid, Alianza Editorial.

DONÉZAR DÍEZ DE ULZURRUN, J.M. (1975): La desamortización de Mendizábal en Navarra, 1836-1851. Madrid, Consejo Superior de Investigaciones Científicas, Instituto Jerónimo Zurita.

FERNÁNDEZ RODRIGUEZ, A. (1979): “Título I. De los foros, subforos y otros gravámenes análogos. Artículos $3^{\circ}$ a 46””. En COMENTARIOS AL CÓDIGO CIVIL Y COMPILACIONES FORALES. TOMO XXXII. COMPILACIÓN DE GALICIA (1979). Jaén, EDERSA, pp. 13 a 83. 
FERRAGUT BONET, J. (1974): "La Desamortización de Mendizábal en Mallorca (18361846)". Boletín Oficial de la Cámara Oficial de Comercio, Industria y Navegación de Palma de Mallorca, no 684-685, pp. 125-179.

GARCÍA GONZALEZ, M.J. (1994): La desamortización de Mendizábal y Espartero en el Bierzo. León, Diputación Provincial de León.

GARCÍA GONZALEZ, M.J. (1996): La desamortización de Madoz en El Bierzo. Ponferrada, Institución "Virgen de la Encina".

GIL, J. (1880): De los Censos según la Legislación General de España. Indicaciones. Santiago, Tipografía de José M. Paredes.

Cuenca, no 33, pp. 101-113GONZÁLEZ MARZO, F. (1993): La desamortización de Madoz en la provincia de Cuenca (1855/ 1886). Cuenca, Excma. Diputación Provincial de Cuenca.

LABRADOR, C. (1850): Economía político-práctica o examen del proyecto de arreglo de la deuda de España. Madrid, Imp. Sres. de Andrés y Díaz.

LÓPEZ PUERTA, L. (1989): La Desamortización Eclesiástica de Mendizábal en la Provincia de Guadalajara: (1836-1851). Guadalajara, Diputación Provincial de Guadalajara.

MADOZ, P. (1846-1850): Diccionario geográfico-estadístico-histórico de España y sus posesiones de ultramar. Madrid, Establecimiento tipográfico de P. Madoz y L. Sagasti.

MOLI FRIGOLA, M. (1975): La desamortización en la provincia de Gerona (1835-1854). (Resumen de la Tesis Doctoral presentada para la obtención del grado de Doctor de Historia Moderna y Contemporánea). Barcelona, Universidad Autónoma de Barcelona.

MORO BARREÑADA, J.M. (1981): La desamortización en Asturias. Oviedo, Silverio Cañada editor.

MORO BARREÑADA, J.M. (1981b): “La desamortización de Madoz en Asturias”. Estudios de Historia Social, no 18-19, pp. 85-165.

NARANJO SANGUINO, M.A. (1997): La desamortización de Mendizábal-Espartero en la provincia de Badajoz (1836-1852). Badajoz, Departamento de Publicaciones de la Diputación Provincial de Badajoz.

ORTEGA CANADELL, R. (1982): Las desamortizaciones de Mendizábal y Madoz en Soria. Soria, Caja General de Ahorros y Préstamos de la Provincia de Soria.

RUEDA HERNANZ, G. (1993): “La desamortización en la Península Ibérica”. Ayer, no 9.

RUEDA HERNANZ, G. (1997): La desamortización en España: un balance (1766- 1924). Madrid, Arco Libros.

SÁNCHEZ GÓMEZ, M.A. (1994): La desamortización en Cantabria durante el siglo XIX (1800-1889). Torrelavega, Excmo. Ayuntamiento de Torrelavega.

SÁNCHEZ RECIO, G. (1986): La Desamortización de Mendizábal en la provincia de Alicante. El clero regular: 1836-1850. Alicante, Instituto de Estudios Juan Gil-Albert, Diputación Provincial.

SOLSONA I SORROSAL, C. (1998): La desamortització eclesiàstica a la província de Lleida (1838-1851). Lleida, Servei de Publicacions Universitat de Lleida.

TURZA Y SAEZ, V. (1859): Manual de desamortización civil y eclesiástica. Badajoz, Imprenta de Arteaga.

VALLEJO POUSADA, R. (1991): “Desamortización de Mendizábal y transformación del régimen de propiedad de la tierra: la redención de censos como vía formal". Pontevedra, 1836-1843. Agricultura y Sociedad, no 61, pp. 97-130.

VALLEJO POUSADA, R. (1992): "Redención y pervivencia del foro durante la desamortización de Mendizábal (1836-1854)". Anuario de Historia del Derecho Español, no 62, pp. 477-500.

VALLEJO POUSADA, R. (1993): A desamortización de Mendizábal na provincia de Pontevedra, 1836-1844. Pontevedra, Diputación Provincial. 
VALLEJO POUSADA, R. (1995): “La desamortización de Mendizábal en Galicia: un estado de la cuestión”. En DONEZAR, J.M. y PÉREZ LEDESMA, M, (eds.): Antiguo Régimen y liberalismo. Homenaje a Miguel Artola. 2. Economía y sociedad. Madrid, Alianza Editorial, pp. 353-366.

VALLEJO POUSADA, R. (2011): "The Survival of the foros in Galicia after Disentailment". Comunicación en XXIII Seminari d'Història Econòmica y Social. Les practiques enfitèutiques a l'època Moderna i Contemporània. Una perspectiva comparada. Universitat de Girona, 1618 de juny de 2011.

VILLARES PAZ, R. (1978): "No cincuentenario da lei de redención de foros (1926-1976). Aproximación ao problema”. Grial, no 54, pp. 477-489.

VILLARES PAZ, R. (1994): Desamortización e réxime de propiedade. Vigo, Edicións A Nosa Terra 
APÉNDICE 1.Venta de foros y censos bienes nacionales (1839-1844) (reales)

Foros y censos adjudicados por la Junta Superior de Venta de Bienes Nacionales entre febrero 1839 y julio 1844

\begin{tabular}{|l|l|c|c|c|c|}
\hline \multicolumn{1}{|c|}{ Comunidad } & Provincia & Número & Tasación & Venta & $\begin{array}{l}\text { \% sobre } \\
\text { total }\end{array}$ \\
\hline Galicia & Coruña & 2666 & 38655870,44 & 53295618,74 & $25,37 \%$ \\
\hline Galicia & Lugo & 2625 & 27668346,35 & 30707429,53 & $14,61 \%$ \\
\hline Galicia & Ourense & 1976 & 21675699,41 & 24002727,26 & $11,42 \%$ \\
\hline Galicia & Pontevedra & 4429 & 32589126,32 & 37046991,18 & $17,63 \%$ \\
\hline Galicia & & 11696 & 120589042,53 & 145052766,71 & $69,04 \%$ \\
\hline Castilla León & Burgos & 119 & 12459993,59 & 16421383,65 & $7,82 \%$ \\
\hline Castilla León & León & 65 & 4337512,88 & 4706486,21 & $2,24 \%$ \\
\hline Castilla León & Palencia & 52 & 3232696,74 & 3531328,00 & $1,68 \%$ \\
\hline Castilla León & Salamanca & 3 & 148457,18 & 228907,00 & $0,11 \%$ \\
\hline Castilla León & Segovia & 1 & 8000,00 & 13100,00 & $0,01 \%$ \\
\hline Castilla León & Valladolid & 10 & 704707,65 & 1211547,32 & $0,58 \%$ \\
\hline Castilla León & Zamora & 67 & 3117646,79 & 3224268,00 & $1,53 \%$ \\
\hline Castilla León & & 317 & 24009014,82 & 29337020,18 & $13,96 \%$ \\
\hline Asturias & Oviedo & 975 & 16750283,56 & 22469437,82 & $10,69 \%$ \\
\hline Comunidad Valenciana & Valencia & 226 & 6913321,50 & 7782072,50 & $3,70 \%$ \\
\hline Castilla La Mancha & Cuenca & 50 & 880188,26 & 1366925,88 & $0,65 \%$ \\
\hline Castilla La Mancha & Guadalajara & 5 & 853833,94 & 1306000,00 & $0,62 \%$ \\
\hline Castilla La Mancha & Toledo & 10 & 1384091,76 & 1677001,00 & $0,80 \%$ \\
\hline Castilla La Mancha & & 65 & 3118113,97 & 4349926,88 & $2,07 \%$ \\
\hline Cantabria & Santander & 46 & 226117,15 & 357053,35 & $0,17 \%$ \\
\hline Extremadura & Badajoz & 40 & 256105,15 & 256626,12 & $0,12 \%$ \\
\hline Cataluña & Barcelona & 1 & 30577,62 & 58700,00 & $0,03 \%$ \\
\hline Cataluña & Gerona & 1 & 92443,12 & 119520,00 & $0,06 \%$ \\
\hline Cataluña & & 2 & 123020,74 & 178220,00 & $0,08 \%$ \\
\hline Euskadi & Álava & 2 & 55400,00 & 82200,00 & $0,04 \%$ \\
\hline Andalucía & Córdoba & 8 & 173141,12 & 199320,53 & $0,09 \%$ \\
\hline Aragón & Teruel & 1 & 48000,00 & 48000,00 & $0,02 \%$ \\
\hline & & 13378 & 172261560,53 & 210112644,09 & \\
\hline TutaL & & & & \\
\hline
\end{tabular}

Fuente: elaboración propia con datos de Gaceta de Madrid 
APÉNDICE 2. Venta de foros y censos bienes nacionales (1836-1854). Comparación de totales de estudios provinciales ${ }^{69}$ con total de Labrador (1850)

\begin{tabular}{|c|c|c|}
\hline \multicolumn{2}{|l|}{ Estudios provinciales } & \multirow[b]{2}{*}{$\begin{array}{c}\% \text { sobre total de } \\
\text { España de C Labrador }\end{array}$} \\
\hline Provincia & $\begin{array}{l}\text { Adjudicación } \\
\text { (reales) }\end{array}$ & \\
\hline Coruña & 109348609 & $23,41 \%$ \\
\hline Lugo & 48450000 & $10,37 \%$ \\
\hline Pontevedra 1838-1844 & 37738231 & $8,08 \%$ \\
\hline Ourense & 35071156 & $7,51 \%$ \\
\hline Galicia & 230607996 & $49,38 \%$ \\
\hline Oviedo & 28772168 & $6,16 \%$ \\
\hline Burgos & 27643887 & $5,92 \%$ \\
\hline León & 10388960 & $2,22 \%$ \\
\hline Lérida & 4532045 & $0,97 \%$ \\
\hline Soria & 2166858 & $0,46 \%$ \\
\hline Cantabria & 1618155 & $0,35 \%$ \\
\hline Cuenca & 1143430 & $0,24 \%$ \\
\hline Guadalajara $^{70}$ & 896069 & $0,19 \%$ \\
\hline Alicante & 832625 & $0,18 \%$ \\
\hline & & $66,08 \%$ \\
\hline España 1836-1849 Labrador (1850) & 467012284 & \\
\hline
\end{tabular}

Fuente: elaboración propia con datos de investigaciones provinciales y Labrador (1850)

APÉNDICE 3. Redenciones de foros y censos bienes nacionales según estudios provinciales $^{71}$ y Labrador (1850) Etapa de Mendizabal (reales)

\begin{tabular}{|l|c|c|c|c|}
\hline & años & Capitalización & años & Capitalización \\
\hline Navarra & $1838-1842$ & 9960752 & $1838-1842$ & 9960753 \\
\hline Coruña & $1838-1852$ & 6393554 & $1838-1849$ & 6034655 \\
\hline Ourense & $1838-1851$ & 5079504 & $1838-1849$ & 1216581 \\
\hline Lugo & $1838-1854$ & 4595000 & $1838-1849$ & 1864000 \\
\hline Mallorca & $1836-1846$ & 1637350 & $1836-1846$ & 1637350 \\
\hline Cantabria & $1843-1846$ & 1618155 & $1843-1846$ & 1618155 \\
\hline Oviedo & $1836-1852$ & 1328587 & $1836-1849$ & 1313024 \\
\hline León & $1838-1850$ & 862825 & $1838-1849$ & 861725 \\
\hline Alicante & $1839-1845$ & 445609 & $1839-1845$ & 445609 \\
\hline Pontevedra & $1838-1843$ & 207687 & $1838-1843$ & 207687 \\
\hline Cuenca & $1839-1844$ & 183146 & $1839-1844$ & 183146 \\
\hline Lérida & $1838-1851$ & 56191 & $1838-1851$ & 56190 \\
\hline Total & & 32368360 & & 25398875 \\
\hline Total Labrador $(1850)$ & & $1836-1849$ & 168307638 \\
\hline
\end{tabular}

Fuente: elaboración propia con datos de investigaciones provinciales y Labrador (1850)

${ }^{69}$ Los datos provinciales proceden de Cordero (2012); Domínguez et al. (1995); Villares (1994); Vallejo (1993); Moro (1981a); Santamaría (2003); Aguado (2002); Solsona (1998); Ortega (1982); Sánchez (1994); González (1989); López (1989); Sánchez (1986).

70 En Guadalajara es el valor de capitalización, no de adjudicación.

${ }^{71}$ Los del Apéndice 2 y Ferragut (1974). 
APÉNDICE 4 Enajenación de rentas en la etapa de Madoz (1855-1867) (reales)

\begin{tabular}{|c|c|c|c|}
\hline & \multicolumn{2}{|c|}{ Venta de rentas } & Redención \\
\hline Año & Capitalización & Remate & Capitalización \\
\hline $1855-56$ & & & 174684210,0 \\
\hline 1859 & & & 34227947,2 \\
\hline 1860 & 196081 & 206501,7 & 39847074,1 \\
\hline 1861 & 2621033 & 2838424,0 & 3342411,7 \\
\hline 1862 & 1913882,4 & 2074811,9 & 18852015,7 \\
\hline 1863 & 46499,8 & 46655,0 & 22628218,5 \\
\hline 1864 & 447310,4 & 558376,0 & 14996962,5 \\
\hline 1865 & 1171070,8 & 1250771,0 & 16914367,8 \\
\hline 1866 & 340608,3 & 379381,8 & 31717703,3 \\
\hline 1867 & 930139,4 & 931088,4 & 31807817,1 \\
\hline Total & 7666625,8 & 8286009,8 & 389018727,8 \\
\hline
\end{tabular}

Fuente: Gaceta de Madrid y Anuarios Estadísticos

APÉNDICE 5.Redenciones de censos en la desamortización de Madoz (1855-1860) Número y capitalización (en miles de reales)

\begin{tabular}{|l|c|c|c|c|c|c|c|}
\hline & \multicolumn{2}{|c|}{ Total } & Clero & Propios & $\begin{array}{c}\text { Benefi- } \\
\text { cencia }\end{array}$ & $\begin{array}{c}\text { Instruc- } \\
\text { ción }\end{array}$ & Estado \\
\hline Comunidad & Número & $\begin{array}{c}\text { Capitali- } \\
\text { zación }\end{array}$ & $\begin{array}{c}\text { Capitali- } \\
\text { zación }\end{array}$ & $\begin{array}{c}\text { Capitali- } \\
\text { zación }\end{array}$ & $\begin{array}{c}\text { Capitali- } \\
\text { zación }\end{array}$ & $\begin{array}{c}\text { Capitaliz } \\
\text { ación }\end{array}$ & $\begin{array}{c}\text { Capitali- } \\
\text { zación }\end{array}$ \\
\hline Andalucía & 30237 & 53559 & 18561 & 23459 & 9015 & 1417 & 1105 \\
\hline Castilla y León & 19893 & 35592 & 22200 & 4830 & 5915 & 2238 & 407 \\
\hline Cataluña & 17746 & 28535 & 19005 & 2475 & 5634 & 1166 & 254 \\
\hline Galicia & 10864 & 21691 & 14869 & 198 & 3596 & 2504 & 522 \\
\hline Madrid & 1994 & 21357 & 10556 & 1123 & 5455 & 3386 & 834 \\
\hline Aragón & 11592 & 18975 & 13157 & 3516 & 1525 & 370 & 405 \\
\hline Castilla_La & & & & & & & \\
Mancha & 8080 & 14505 & 4135 & 8276 & 1755 & 215 & 122 \\
\hline Extremadura & 7937 & 13800 & 7045 & 5590 & 890 & 235 & 37 \\
\hline CValenciana & 9689 & 10142 & 7115 & 941 & 1865 & 147 & 73 \\
\hline Navarra & 1466 & 6220 & 5765 & 58 & 180 & 212 & 28 \\
\hline Asturias & 4395 & 4635 & 1863 & 333 & 1139 & 1160 & 137 \\
\hline País Vasco & 3688 & 4623 & 3223 & 448 & 776 & 174 & 05 \\
\hline Baleares & 970 & 4523 & 3539 & 191 & 649 & 114 & 29 \\
\hline Murcia & 2972 & 3720 & 1975 & 423 & 460 & 391 & 469 \\
\hline La Rioja & 2053 & 3675 & 2125 & 671 & 619 & 256 & 3 \\
\hline Canarias & 375 & 1861 & 991 & 481 & 318 & 2 & 67 \\
\hline Cantabria & 1609 & 1339 & 453 & 285 & 99 & 489 & 10 \\
\hline Total & 135560 & 248759 & 136583 & 53307 & 39898 & 14486 & 4483 \\
\hline
\end{tabular}

Fuente: elaboración propia con datos de Gaceta de Madrid y Anuarios Estadísticos

Revista Galega de Economía: http:/ / www.usc.es/ econo/ RGE/ benvidag.htm https:/ / ideas.repec.org.s/ sdo/ regaec.html 